\title{
Increasing the Range of Contemporary Artillery Projectiles
}

\author{
Mohammed Amin DALI, Slobodan JARAMAZ, Damir JERKOVIĆ, Danilo DJURDJEVAC
}

\begin{abstract}
The study of increasing range of standard $122 \mathrm{~mm}$ artillery projectile was done mainly by changing the base drag of standard projectile using hollow base shape and base bleed unit. The drag reduction in the case of the projectile with base bleed was up to $20 \%$ compared to the standard projectile, and in the case of the hollow base projectile, the drag reduction reaches $8 \%$. Optimisation of base drag reduction was done by using the computational fluid dynamics software (CFD). CFD analyses enable complete calculation of fluid parameters behind the projectile base and determination of base bleed burning gases influence on flow field. In that way, we determine the pressure on the projectile base in the case of projectile with hollow base or with base bleed. CFD computations give us relation between base drag reduction and characteristics of base bleed grain. Using the CFD results in the modified 6-degree of freedom (6-DOF) projectile trajectory model, we calculate ranges of projectiles. The verification of estimated range increase by projectile modification was done by comparison with experimental results obtained on firing range. Comparison of measured range and results from 3-D radar show good compatibility with theoretical results from the modified 6-DOF.
\end{abstract}

Keywords: artillery projectiles; base bleed; CFD; drag reduction; hollow base; range extension; 6-DOF

\section{INTRODUCTION}

Extended range and greater accuracy are constant objectives when new ammunition is developed or when existing ammunition is modified. Aerodynamic bodies such as projectiles, missiles, and rockets generally, undergo deterioration of flight performance by drag. Reducing the drag acting on a supersonic projectile is a challenging task. During the projectile's flight, the low pressure in the afterbody region is responsible for up to $50 \%$ of the total drag [1]. Reducing the base drag is an efficient and practical way to reduce the total drag of projectile. Two methods of drag reduction are typically used. The first is to optimize the shape of the projectile, typically through the use of a boat tailed afterbody which reduces the base surface area exposed to the afterbody expansion. The second method consists of increasing the pressure behind the projectile. This can be accomplished with injection of a low velocity fluid in the recirculation region directly behind the base. In Fig. 1, various methods of drag reduction are summarized [2].

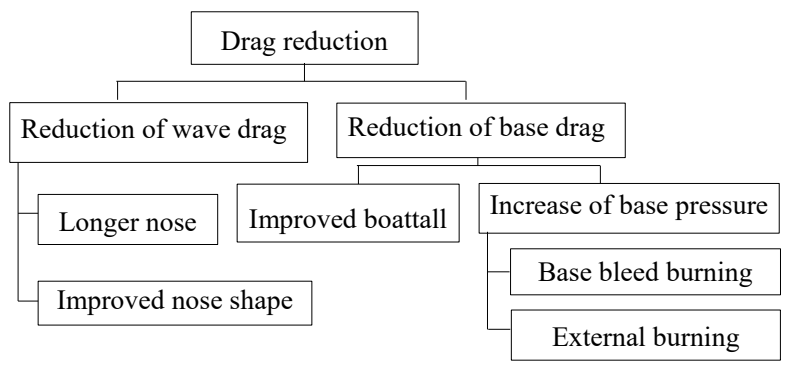

Figure 1 Various methods used for drag reduction

In addition, in order to extend volume of propellant chamber in the cannon and getting more stable projectile, a new shape of projectile base was invented- it is, so called, the hollow base projectile. The purpose of this study, is improving the range performance of standard projectile using the hollow base shape and the base bleed unit. The study was performed on the calibre $122 \mathrm{~mm}$.

\section{PROJECTILES USED}

In this study, in order to confirm the effectiveness of hollow base shape and base bleed in the range extension of the artillery ammunition, three types of $122 \mathrm{~mm}$ projectiles are used. The first one is the standard projectile known as 122 ST, the second one is with hollow base shape known as $122 \mathrm{HB}$ and the third type is with base bleed known as 122_BB. All three types are shown in Fig. 2.

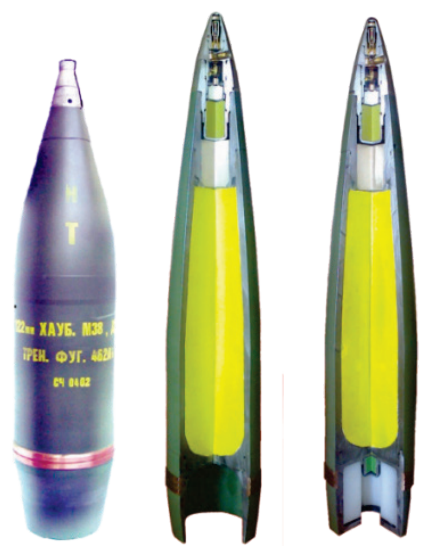

Figure 2. The projectiles used in this study (from left to right): standard projectile (122_ST), the hollow base projectile (122_HB) and projectile with base bleed $\left(122 \_B B\right)$

The last two are still in the testing phase. In Tab. 1 some projectiles characteristics are given:

Table 1 The geometric characteristics of the projectiles used in this study

\begin{tabular}{|l|c|c|c|}
\hline \multicolumn{1}{|c|}{ Projectile } & $122 \_\mathrm{ST}$ & $122 \_\mathrm{HB}$ & $122 \_\mathrm{BB}$ \\
\hline Caliber $(\mathrm{mm})$ & 122 & 122 & 122 \\
\hline $\begin{array}{l}\text { The average mass / standard } \\
\text { projectile mass }\end{array}$ & 1 & $\sim 0,97$ & $\sim 1$ \\
\hline$I_{x}\left(\mathrm{~kg} \mathrm{~mm}^{2}\right)$ & $\sim 45600$ & $\sim 42800$ & $\sim 45800$ \\
\hline$I_{y}=I_{z}\left(\mathrm{~kg} \mathrm{~mm}^{2}\right)$ & $\sim 412000$ & $\sim 486000$ & $\sim 570000$ \\
\hline $\begin{array}{l}\text { Total length / standard projectile } \\
\text { total length }\end{array}$ & 1 & $\sim 1,18$ & $\sim 1,18$ \\
\hline $\begin{array}{l}\text { The diameter of the base / the } \\
\text { diameter of the base of standard } \\
\text { projectile }\end{array}$ & 1 & $\sim 1,14$ & $\sim 1,23$ \\
\hline
\end{tabular}




\section{COMPUTATIONAL APPROACH}

This section describes the physical and numerical models chosen for the present study, and contains two main objectives. The first one is a numerical simulation of flow field around axisymmetric body projectiles, which was obtained with the Reynolds Averaged Navier-Stokes (RANS) [3, 4] computational fluid dynamics software (CFD). In order to estimate the drag coefficient of projectile's body, three turbulence models $k-\omega S S T$ (The shear stress transport) (2 equations), transition $k-k l-\omega(3$ equations) and Reynolds Stress Model RSM (5 equations), are used [3]. These models were tested and validated with the semi-empirical model $(A D K O)$ using aerodynamic prediction used in [5]. Also these results were compared with experimental results obtained by $3 \mathrm{D}$ radar for all of projectile's types.

The second objective will be dedicated to using these CFD results in the Six Degree of Freedom trajectory computer code (6-DOF) for determination of the theoretical trajectories of each used artillery projectile, and comparing them with the experimental results captured by 3D radar.

\subsection{Governing Equations and Turbulence Models}

The equations considered in this study for a compressible fluid flow behind projectile base are $[3,6,7]$ : Continuity:

$$
\frac{\partial \rho}{\partial t}+\frac{\partial\left(\rho u_{i}\right)}{\partial x_{i}}=0
$$

\section{Momentum:}

$\frac{\partial\left(\rho u_{i}\right)}{\partial t}+\frac{\partial\left(\rho u_{i} u_{j}\right)}{\partial x_{j}}=-\frac{\partial P}{\partial x_{i}}+\frac{\partial}{\partial x_{i}} \tau_{i j}$

Energy:

$$
\begin{aligned}
& \frac{\partial}{\partial t}\left[\rho\left(e+\frac{V^{2}}{2}\right)\right]+ \\
& +\frac{\partial}{\partial x_{j}}\left[\rho u_{j}\left(e+\frac{V^{2}}{2}\right)+P+q_{j}-u_{i} \tau_{i j}\right]=0
\end{aligned}
$$

Note that $\mathrm{u}$ denotes instantaneous velocity, $V$ velocity modulus, $\rho$ gas density, $\mathrm{p}$ gas pressure, $q_{j}$ heat flux and $\tau_{i j}$ viscous stress tensor. In addition, the perfect gas equation of state was considered. For the closure of the system, three turbulence models are used, $k-\omega S S T$, Transition $k-k l-\omega$ and Reynolds Stress Model RSM, Default constant values were employed for these models [3, 7].

\subsection{Hypothesis and Boundary Conditions}

A steady state problem was considered for the computations. Despite the body flight being a transient process, the characteristic time of variation of the boundary conditions was considered bigger than the characteristic residence time of the fluid particle within the domain. This means that the transient terms in the mass, momentum, and energy conservation equations were negligible compared to the convective terms. Therefore, the simulations were performed considering steady state boundary conditions for different flight conditions: flight Mach number, Base Bleed propellant gas mass flow rate, the atmospheric pressure, and the temperature at the flight altitude. The atmospheric conditions, considered as stagnation conditions, were calculated by International Standard Atmosphere model.

This way, different flight conditions cases were simulated to obtain the body drag coefficient at different Mach numbers, and different mass flux injection in the case of projectile with base bleed. The fluid considered in the simulations was air and propellant combustion gases. For both gases, the ideal gas assumption was used. Constant values were assumed for heat capacities. The Sutherland law for variable dynamic viscosity was used due to the high temperature ranges encountered in the problem studied, especially in the base bleed configuration. The projectiles were assumed to fly under zero angle of attack. All the walls were considered adiabatic. The flow field was considered compressible and the far field conditions were imposed at the external boundary, where the flight Mach number, pressure and temperature (stagnation values) were introduced. The entire domain was initialized with these far field conditions [7].

Regarding the propellant combustion at the Base Bleed unit, the majority of the literature analysed the reduction of the drag with the Base Bleed units, but the problem of the flow field in the Base Bleed cavity was neglected. The simple approach was considered; the combustion process was modelled as normal injecting of gas mass flow rate at a fixed temperature through the orifice. The temperature and mass flow rate values were obtained from the propellant combustion data. The mass flow rate and temperature of combustion gases were estimated to be constant during the constant Mach number. The relative chamber pressure was estimated from the static experimental combustion tests. The thermodynamic parameters and the composition of combustion products are introduced. They were obtained with the help of the thermochemical calculation (TERMO code), which is developed based on [8]. We considered that at the orifice, only propellant gas exists, and at the far field exists only the air.

\subsection{Body Geometry and Base Bleed Unit Model}

The projectile body was modelled as axisymmetric. The grid was made in mesh software. The numerical structured discretization of the computational domain around the model was done with quadrilateral cells with $\left(y^{+} \sim 1\right)$, and afterwards exported to the software ANSYSFLUENT $^{\mathrm{TM}}$ in order to simulate the flow around the projectile. In the case of the projectile with base bleed, the model Species must be turned on (used as Species Transport). The species used in the CFD simulation are presented in Tab. 2.

These species were obtained with the help of the thermochemical calculation for the (AP/HTPB+Fe/ additives) Base bleed grain integrated in the projectile. 
Table 2 The molar fractions of main species generated during the base bleed grain combustion

\begin{tabular}{|c|c|}
\hline Species & The molar fraction \\
\hline $\mathrm{H}_{2}$ & $3,427 \mathrm{E}-01$ \\
\hline $\mathrm{CO}$ & $3,271 \mathrm{E}-01$ \\
\hline $\mathrm{HCl}$ & $1,225 \mathrm{E}-01$ \\
\hline $\mathrm{H}_{2} \mathrm{O}$ & $1,131 \mathrm{E}-01$ \\
\hline $\mathrm{N}_{2}$ & $6,361 \mathrm{E}-02$ \\
\hline $\mathrm{CO}_{2}$ & $3,045 \mathrm{E}-02$ \\
\hline $\mathrm{FeCl}_{2}$ & $5,345 \mathrm{E}-04$ \\
\hline
\end{tabular}

\subsection{The pressure of Combustion Products at the Outlet of the Orifice}

Because the approach we considered is based on the injection of a gas mass flow rate and neglects the flow field in the Base Bleed cavity, the CFD simulation needs the introduction of the Supersonic/Initial Gauge Pressure. This notion specifies that overpressure value at the orifice outlet is relative to the base pressure. This pressure can be obtained from the static experimental combustion tests shown in Fig. 3.

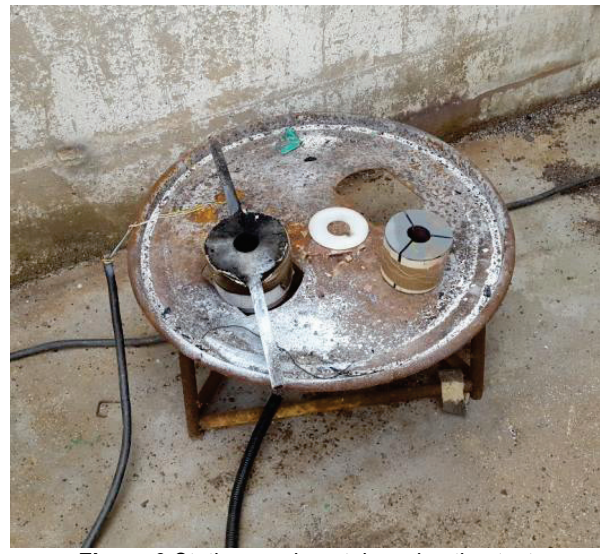

Figure 3 Static experimental combustion test

In our study, this test resulted in a chamber gauge pressure profile with values of overpressure from 0 to 75 mbar (see Fig. 5). Therefore, in all CFD simulations related to the base bleed projectiles, we used a value of $6000 \mathrm{~Pa}$ as a Supersonic/Initial Gauge Pressure, [3].

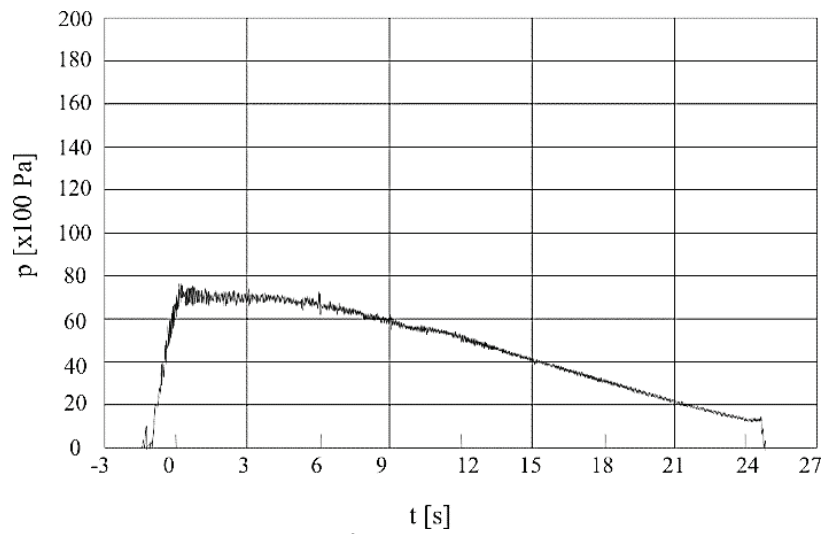

Figure 4 The obtained results from the static experimental combustion test $\left(P \_\right.$over $\left.=f(t)\right)$.

\subsection{Simulations Overview}

Computations were performed using the generalpurpose software ANSYS-FLUENT ${ }^{\mathrm{TM}}$. The whole set of equations was solved by using an implicit pressure based solver with a second order upwind discretization scheme, Least Squares cell based method for gradient calculations and ROE-Flux-Difference Splitting flux evaluation schemes (ROE-FDS) [7, 9], ROE-FDS scheme has shown to give good results when dealing with compressible flow problems.

\subsection{The 6-DOF Description}

Comparing to the Modified Point Mass Model (MPMM), the 6-DOF (three rotational DOF and three linear DOF, see Fig. 5) model is more accurate, and it is useful when dynamic wings are added (Rocket and Missiles). 6-DOF model is used because it can depict all forces and moments during the flight and increase the physical understanding of which parameters have the highest impact on the flight trajectory. This model requires more aerodynamic coefficients and significantly more computing power $\left(C_{x}, C_{y}, C_{z}, C_{l}, C_{m}, C_{n} \ldots\right)$ [10]

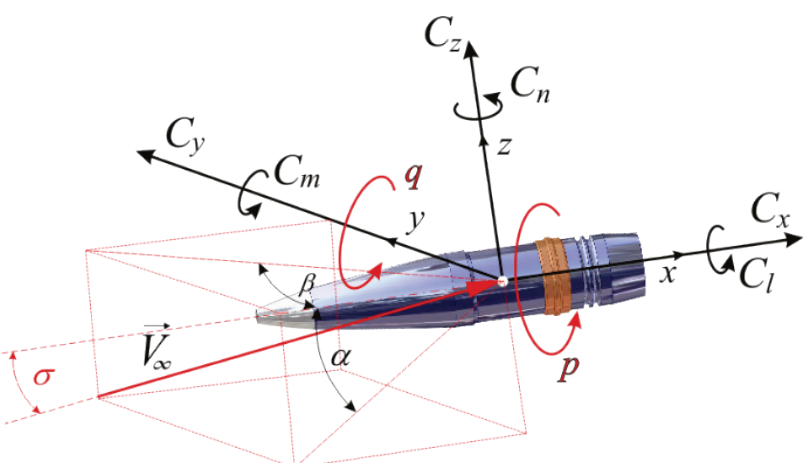

Figure 5 The body coordinate axes $x$, y and $z$, orientation of aerodynamic coefficients and moments and angle of attack

The 6-DOF model is the most complex model in the field of exterior ballistics; it gives the most accurate solution possible. The projectile is assumed rigid and rotationally symmetric. The 6 -DOF model contains two vector differential equations of motion $[11,12]$. There are two highly coupled vector differential equations (Bold characters denote vectors) [8-14].

$$
\begin{aligned}
& \frac{\mathrm{d} \boldsymbol{V}}{\mathrm{d} t}=-\frac{\rho v S C_{D}}{2 m} \boldsymbol{v}+\frac{\rho S C_{L_{\alpha}}}{2 m}\left[v^{2} \boldsymbol{x}-(\boldsymbol{v} \cdot \boldsymbol{x}) \boldsymbol{v}\right]- \\
& -\frac{\rho S d C_{N_{p \alpha}}}{2 m} \cdot \frac{I_{y}}{I_{x}}(\boldsymbol{h} \cdot \boldsymbol{x})(\boldsymbol{x} \times \boldsymbol{v})+\boldsymbol{g}+\boldsymbol{\Lambda}
\end{aligned}
$$

The Eq. (4) is the linear differential equation, which takes into account drag force, lift force, Magnus force, gravity force and the Coriolis Effect. All forces have been divided with mass to get accelerations [10-15].

The Eq. (5) is the differential vector equation for projectile rotation, including spin-damping moment, overturning moment; Magnus moment and pitch damping moment; all moments have been divided with their corresponding moments of inertia to get rotational accelerations [10]: 


$$
\begin{aligned}
& \frac{\mathrm{d} h}{\mathrm{~d} t}=\frac{\rho v S d^{2} C_{l p}}{2 I_{x}}(\boldsymbol{h} \cdot \boldsymbol{x}) \boldsymbol{x}+\frac{\rho v S d C_{M_{\alpha}}}{2 I_{y}}(\boldsymbol{V} \times \boldsymbol{x})+ \\
& +\frac{\rho S d^{2} C_{M_{p \alpha}}}{2 I_{x}}(\boldsymbol{h} \cdot \boldsymbol{x})[\boldsymbol{v}-(\boldsymbol{v} \bullet \boldsymbol{x}) \boldsymbol{x}]+ \\
& +\frac{\rho v S d^{2}\left(C_{M_{q}}+C_{M_{\dot{\alpha}}}\right)}{2 I_{y}}[\boldsymbol{h}-(\boldsymbol{h} \cdot \boldsymbol{x}) \boldsymbol{x}]
\end{aligned}
$$

The 6-DOF program is described in detail in [10]. The Runge-Kutta $4^{\text {th }}$ order integration method is used with time step of $0,001 \mathrm{~s}$, which was chosen empirically based on stability of simulation [14].

The aerodynamic coefficients used in the calculation for all types of projectiles, are the results supplied by the developed semi-empiric program based on [12, 16, 17]. Of course, this is done after comparing them with the results obtained by the CFD simulation and the results obtained by the 3D radar during the projectile's flight. The coefficients are functions of the angle of attack and Mach number. The evolution of the various thermodynamic parameters (atmospheric pressure $P$, air density $\rho$ and the temperature $T$ ) is defined by the standard atmospheric parameters programmed in MATLAB (subroutine used in code for the flight simulation - atmicao code) based on ISO 2533-1975 [18].

\subsection{Artillery Projectile with Base Bleed}

For the projectile with a base bleed unit, the trajectory was also calculated using differential equations of projectile motion according to the 6-DOF model. As a consequence of existing base bleed unit, in the equation of projectile motion, drag given by Eq. (6) is changed:

$D=C_{0} \frac{\rho_{\infty} v_{\infty}^{2}}{2} A_{\text {ref }}$

During the working time of base bleed unit $\left(t_{g}\right)$, the drag coefficient will be reduced for the value of $\Delta C_{D}$.

$\Delta C_{D}=C_{D B 0}-C_{D B B}$

That means that the total drag coefficient during the burning time of the base bleed unit $\left(t_{g}\right)$ is given by the relation:

$$
C_{D}=C_{D 0}-\Delta C_{D}
$$

The base drag coefficient for the projectile with base bleed is a function of several parameters:

$$
C_{D B B}=f\left(M_{\infty}, I, T_{g}, A_{i}, A_{b}, \beta, M \ldots\right)
$$

In this study is used specific projectile geometry (determined $A_{i}, A_{b}$ ) and specific base bleed grain (determined $a, b, n, T_{g}, R_{g}, k, \rho_{g}$ and $N_{s e g}$ ) whose composition was AP/HTPB + Fe/Additives. Therefore, the base drag reduction (the total drag reduction) will depend only on Mach number and impulse [19]:
$\Delta C_{D}=f\left(M_{\infty}, I\right)$

The impulse $I$ is given by Eq. (11) [19]:

$I=\frac{\dot{m}_{g}}{\dot{m}_{b}}=\frac{r \cdot A_{g} \cdot \rho_{g}}{v_{\infty} \cdot A_{b} \cdot \rho_{\infty}}$

where $r$ is the burning rate of the base bleed grain given by the law [20]:

$r=a+b \cdot P_{g}^{n}$

According to the CFD simulation results obtained by ANSYS-FLUENT ${ }^{\mathrm{TM}}$ software and the obtained results in this study, the relation of drag reduction is formed:

$$
\begin{aligned}
& \Delta C d\left(M_{\infty}, I\right)=-0,3815+0,5500 \cdot M_{\infty}+40,6980 \cdot I- \\
& -0,1552 \cdot M_{\infty}^{2}-17,7310 \cdot M_{\infty} \cdot I-1,5038 e 03 \cdot I^{2}
\end{aligned}
$$

This semi-empirical relation is tested only for $122 \mathrm{~mm}$ projectile with base bleed. This relation is introduced in the range calculation (6-DOF) as a function of $I$ and $M_{\infty}$ as parameters (increased $M_{\infty}$ gives increased base-bleed efficiency).

\subsubsection{Change of Grain Burning Surface during Combustion}

The base bleed grain was of the cylindrical shape with three segments (see Fig. 6). The external surface and one base of this cylinder were inhibited, and all of the internal surfaces and one base were non-inhibited.

The definition of the function of grain burning as a function of burnt web $\left(A_{g}=f(e)\right)$ is described in detail in the study of $[20,21]$.

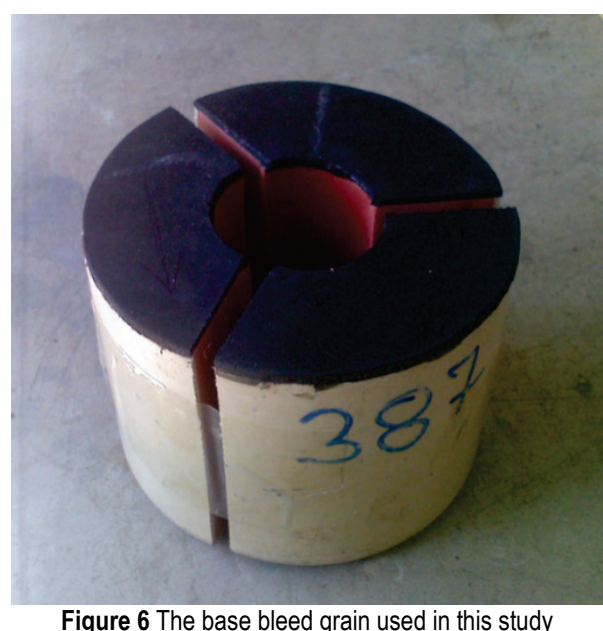

\subsubsection{Pressure in the Base Bleed Chamber}

The pressure in the base bleed chamber is defined using the equality of mass flux of burning products through the orifice and mass flux of gas formed due to the grain burning. For the case when the following inequality is satisfied [20]: 
$\frac{P_{d}}{P_{g}}>\left(\frac{2}{k+1}\right)^{\left(\frac{k}{k-1}\right)}$

The flow of gas from the chamber is subsonic $(M<1)$. Then the mass flux of burning products is given by the following equation $f_{1}\left(P_{d}, P g\right)$ :

$$
\dot{m}_{g}=\rho_{\infty} A_{i}\left(\frac{P_{d}}{P_{g}}\right) \sqrt{\frac{2 k}{k-1} R_{g} T_{g}\left(1-\frac{P_{d}}{P_{g}}\right)^{\left(\frac{k-1}{k}\right)}}
$$

Otherwise, when the condition (14) is not satisfied, the gas flow from combustion chamber is supersonic and mass flux is defined by expression $f_{2}\left(P_{g}\right)$ :

$\dot{m}_{b}=\frac{B P_{g} A_{i}}{\sqrt{R_{g} T_{g}}}$

In the previous expression, the constant $B$ is defined as:

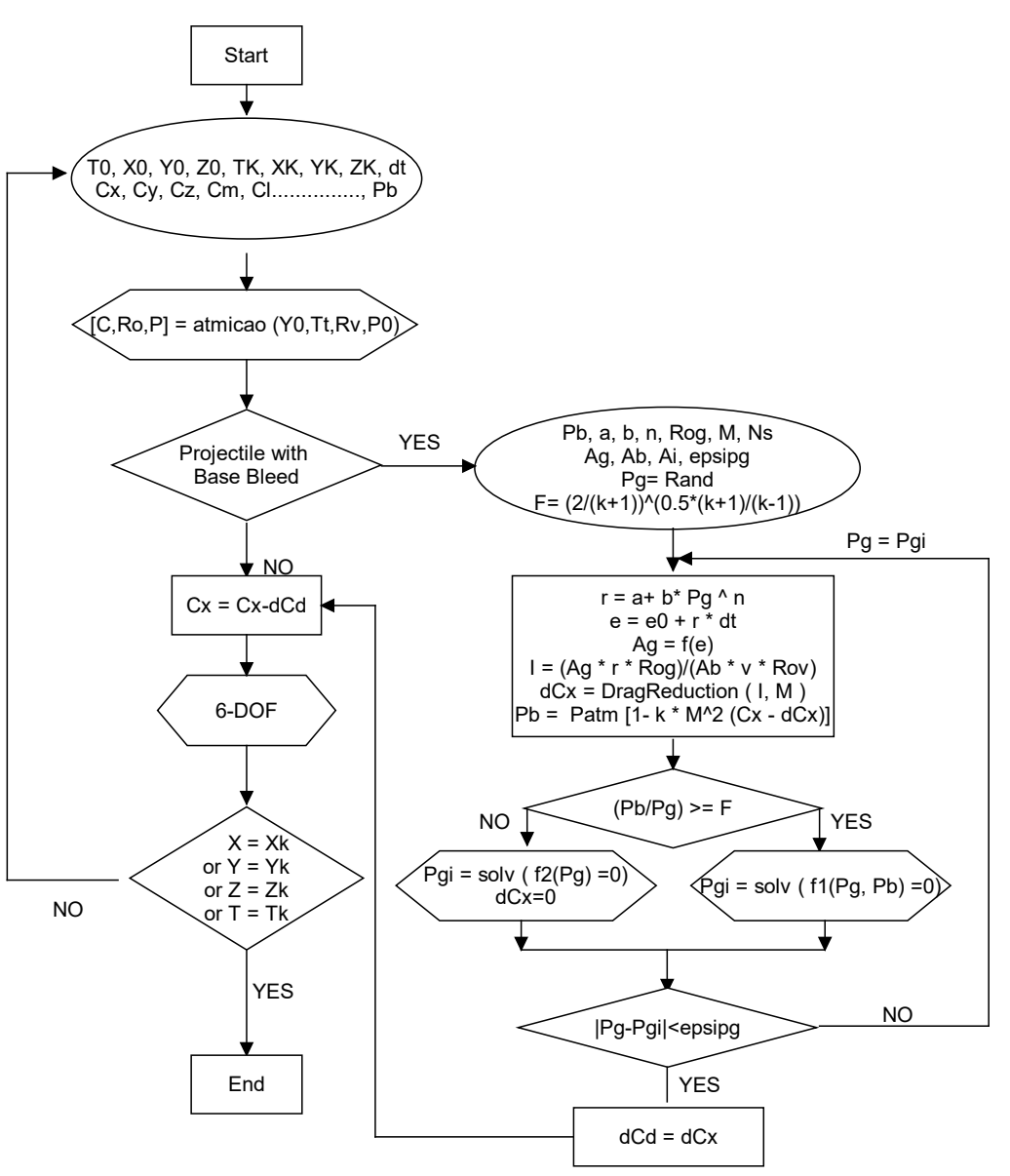

Figure 7 The modified schema used to determine the range of artillery projectiles with base bleed

\section{EXPERIMENTAL INVESTIGATION 4.1 Conditions at the Firing Site}

In practice, when projectiles are indirectly fired, some real input data must be added to increase the probability of
$B=\sqrt{k}\left(\frac{2}{k+1}\right)^{\left(\frac{k+1}{2(k-1)}\right)}$

It should be emphasized that occurrence of supersonic flow in the orifice is undesirable phenomenon for increasing the range. The supersonic flow makes impossible the recirculation of burning products behind projectile and increasing of projectile base pressure. This is the fact which should be given special attention during the selection of grain characteristics. Equalizing mass fluxes $\dot{m}_{g}$ and $\dot{m}_{b}$ leads to equation for the pressure in the base bleed chamber, which is solved iteratively [19].

\subsection{Procedure for Determining Range of Artillery Projectile with Base Bleed}

For determining the range of artillery projectile, modified 6-DOF is used; the term 'modified' is used because of integration in the model possibility to calculate influence of base bleed unit on the projectile trajectory. This program is based on an iterative calculation, and is described in detail in the study of [21].

The flow chart of the program is shown in Fig. 7:

first round hit (the precision) [12]. Variations in wind and temperature have large effect on the trajectory of the projectile. Therefore the weather needs to be measured continuously throughout the day in order to have correct atmospheric conditions. This is usually done by measuring 
the wind, temperature and pressure at different altitudes a few times during the day proving ground firing test with the weather balloon and radio gauge.

In the study, two types of radars are used. The first one is a $V_{0}$ radar type WEIBEL Doppler radar BS-850 used for measuring the initial velocity of the projectiles.

The second one is a 3D radar type WEIBEL Doppler radar MFTR-2100 (The Multi Frequency Trajectory Radar system), which can measure: slant range, azimuth and elevation angles, and 3D trajectory and velocity components. All these measurements are given as a function of flight time [22].

\subsection{Live Firings}

The live fire data comes from the shooting proving ground firing range. The three types of rounds (standard, hollow base and base bleed) were fired by the howitzer $122 \mathrm{~mm}$ D-30 artillery gun. For every type of projectile two groups of five projectiles were fired with an elevation angle equal to $\theta_{0}=14,22^{\circ}$ and with $\theta_{0}=44,70^{\circ}$. The $3 \mathrm{D}$ radar was used for measurement for elevation angle $14,22^{\circ}$. The elevation angle $44,70^{\circ}$ provides the maximum ranges for all types of projectile,

\section{VERIFICATION OF THE THEORETICAL MODEL 5.1 CFD Results}

In order to obtain an efficient model, the numerical simulations were validated against experimental data. After that, the efficiency of different turbulence models was analysed and assessed.

The numerical computations using the steady, viscous Navier-Stokes equations were performed to predict the flow field and aerodynamic coefficients on the nonspinning projectile for jet-on conditions (case for projectile with base bleed).

Two dimensional axisymmetric (2-D) numerical computations have been performed for the projectile configuration with jet interaction using ANSYSFLUENT $^{\mathrm{TM}}$ code at different Mach numbers (from $M=0,4$ to 2,2$)$.

Results were discussed in light of benchmarks between model predictions and experimental data (obtained from radar) and the results obtained from the semi-empiric ADK0 code (aerodynamic prediction code used in [5]).

The different drag coefficient results given by the CFD simulations ( $k-\omega S S T, k-k l-\omega$ and $R S M$ turbulence models) are shown in Fig. 8 together with the semi-empirical results (given by ADK0 code).

From Fig. 8, it can be concluded that the three models gave almost the same curve shape and the same results of drag coefficient for the same projectile type [23].

Comparing the simulation results of the standard projectile (122_ST) with the semi-empirical results, it is clear that they have almost the same drag coefficient value for every Mach number [23]. This confirms that the semiempirical code gives reliable results, which means that it can be used for the drag coefficients determination (case of standard projectile).

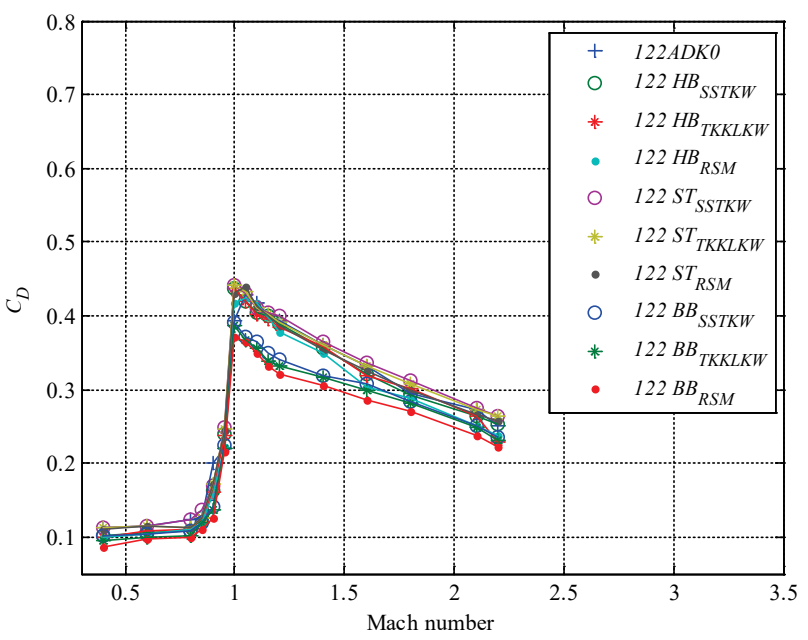

Figure 8 Drag coefficient $C_{D}$ as a function of $M$ for all projectile types (standard projectile ST, hollow base projectile HB and projectile with base bleed $\mathrm{BB}$ ) from CFD simulation using $S S T-k \omega, T k k l-k \omega$ and $R S M$ turbulence models and semiempirical results (given by ADKO code) for the standard projectile.

Besides that, for Mach numbers between 1 and 2,1, which is the velocity domain for projectiles with the base bleed working, there is a drag reduction up to $20 \%$ compared to the standard projectile (122_ST) (in this case the injection of an optimal mass flow rate is done and it is determined in advance - this optimal mass flow rate gave the most possible drag reduction) [23]. In the case of the hollow base projectile (122_HB), the drag reduction reaches up to $8 \%$.

In Fig. 9, the experimental drag coefficient results captured by the 3-D radar for the hollow base projectile and the standard projectile are compared with the mean drag coefficient CFD results for every projectile and semiempirical results (given by ADK0 code).

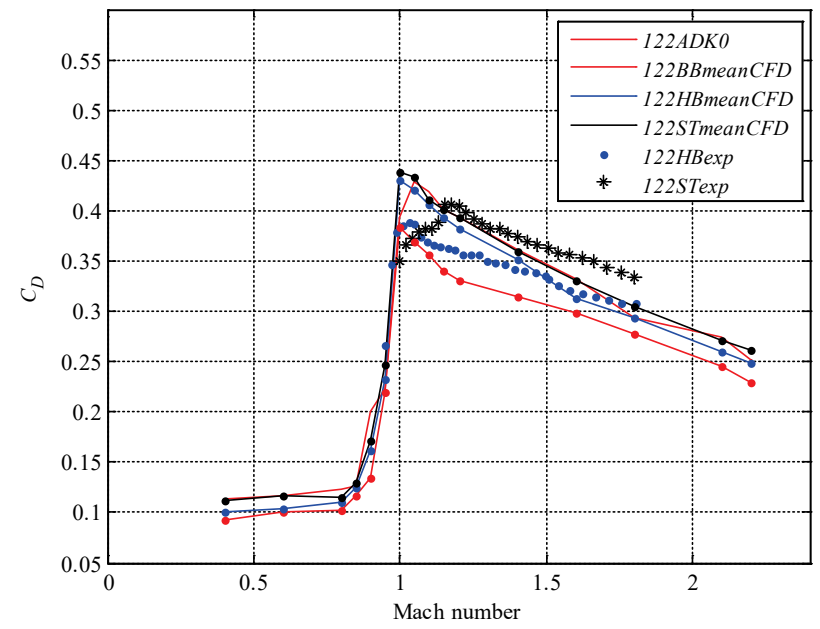

Figure 9. The experimental drag coefficient results $C_{D}$ as a function of $M$ for the hollow base projectile (HB) and the standard projectile (ST) compared to the mean drag coefficient obtained from the CFD for every projectile and semiempirical results.

From the experimental drag coefficient results shown in Fig. 9, it can be said that there is a drag reduction in the case of hollow base projectile (122_HB) compared to the standard projectile (122_ST).

The shift between the CFD and the experimental drag coefficient results is the consequence of the noise in the signals, which increases the error of real velocity 
measurements on the one hand. On the other hand in the performed CFD solutions with these computer code inherent are errors or uncertainties in the results. These inherent inaccuracies are due solely to the fact that we are approximating a continuous system by a finite length, discrete approximation $[22,24]$.

\subsection{Trajectory Analysis}

In this section, the 6-DOF model was compared with the firing table data for $122 \mathrm{~mm} \mathrm{D-30} \mathrm{howitzer} \mathrm{and} \mathrm{to} \mathrm{the}$ 3-D radar captured results. The verification was performed by using measured initial velocity and elevation in the model. The range and drift from the firing table for those inputs were compared to the model outputs and the experimental results. As mentioned earlier in section 3.7, the firing table is made by using Modified Point Mass Model (MPMM), which means that the firing table did not take into account Coriolis Effect and the angular velocities according to $Y$ and $Z$-axis.

In Fig. 10 is shown the experimental trajectory and calculated trajectory for the three projectile types for the elevation angle equal to $\theta_{0}=14,22^{\circ}$.

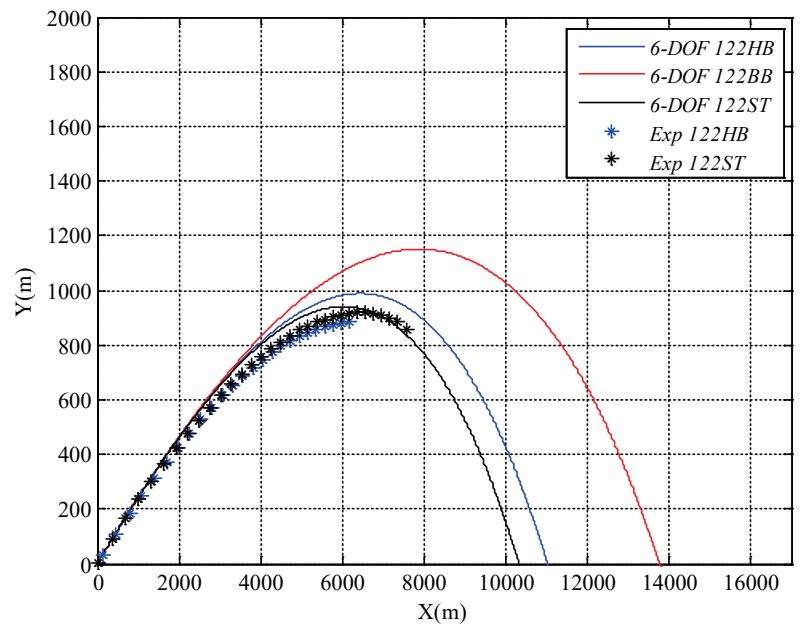

Figure 10. The experimental trajectory $(Y=f(X))$ compared to 6-DOF model results for the three projectile types $\left(\theta_{0}=14,22^{\circ}\right)$.

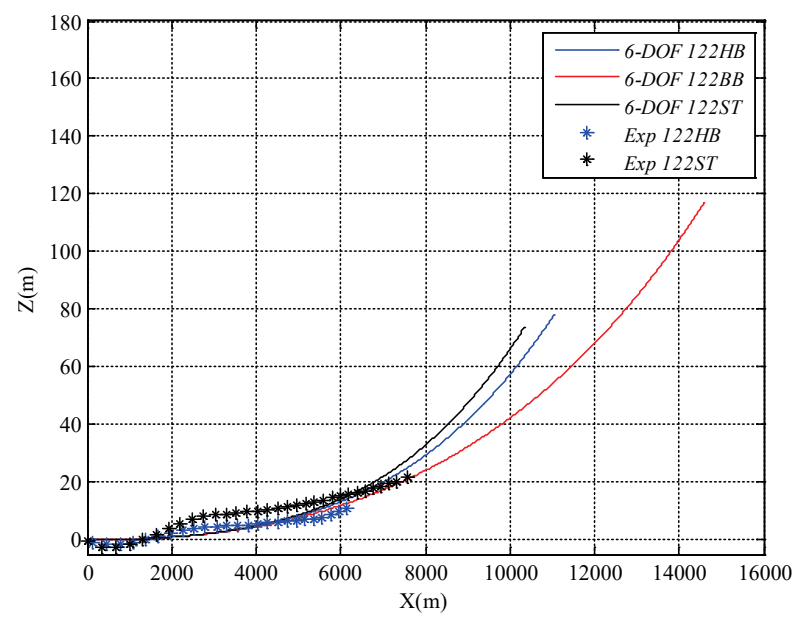

Figure 11. The experimental drift results $(Z=f(X))$ compared to 6-DOF model results for the three projectile types $\left(\theta_{0}=14,22^{\circ}\right)$.

The whole trajectory could not be captured by $3-\mathrm{D}$ radar, because of the forest on firing range which made the capture impossible. In the case of projectile with base bleed $(122 \mathrm{BB})$ the capture was unsuccessful because of the long distance between the radar and the canon muzzle (This projectile is still in the development phase; hence, this distance was chosen as a safety precaution).

Still, there is the small difference between the trajectory estimated by the 6-DOF model and experimental results given by the 3-D radar; the difference is almost $\sim 8 \%$ in the case of (122_HB) and $\sim 1 \%$ in the case of (122_ST).

In Fig. 11, the drifts are compared for the 6-DOF model and experimental results given by the 3 -D radar. The positive drift is defined as yaw to the left when viewing downrange (from the howitzer towards the target) perpendicular to the trajectory.

Generally, the drift appears because of the interaction between the rotating projectile (which has the high spine) and the movement of the air, which generates the new lateral force (see Fig. 12); this phenomenon is called the Magnus effect [25]. Because of this phenomenon and the wind direction [25], it should always be made a correction when the firing tables are used.

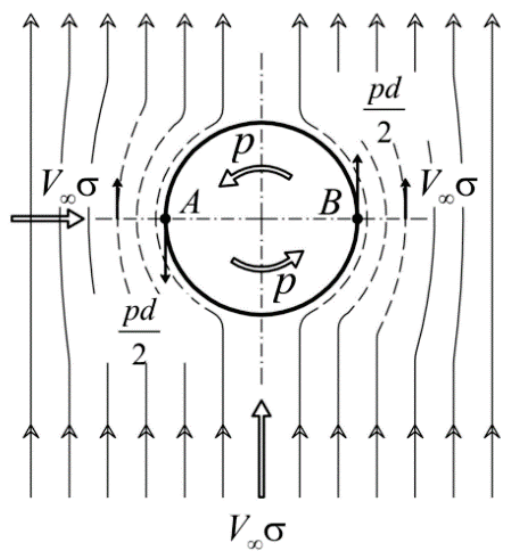

Figure 12 An explanatory schema illustrates the Magnus phenomenon and how it generates the lateral force

From Fig. 11 it could be seen that the projectile's drift and the projectile range (fly time) are directly proportional.

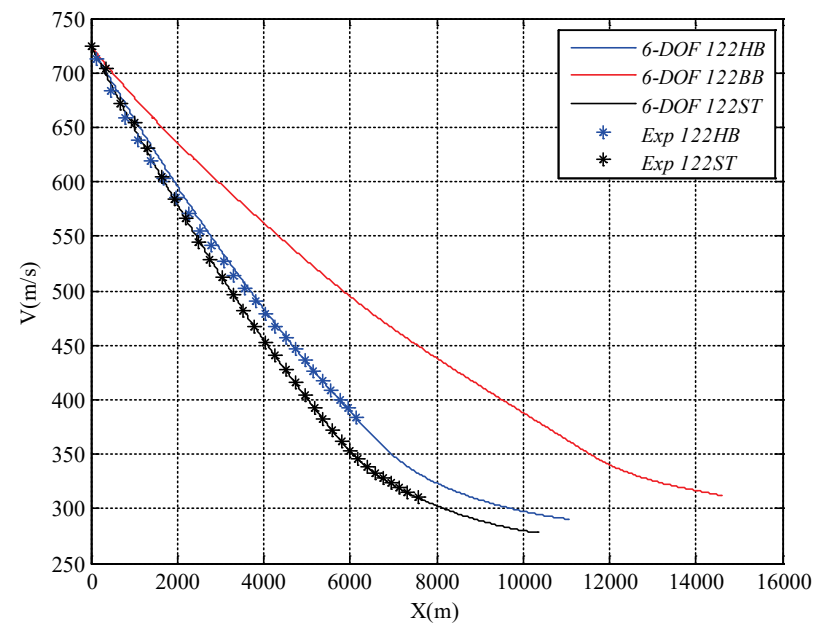

Figure 13 The experimental velocity profile $(V=f(X))$ compared to 6-DOF model results for the three projectile types $\theta_{0}=14,22^{\circ}$

When we look at the part where radar measurement is considered, we can see that the experimental results and those estimated by the 6-DOF model have almost the same 
curve. The difference between them can be justified by the vibration of the canon during the shooting.

Velocity profiles for the three types of projectiles are summarized in Fig. 13.

The experimental results and those estimated by the 6DOF model are almost identical, which confirms the reliability of our programmed model.

In the case of the projectile with base bleed, the decreasing of the projectile's velocity is less than in the case of standard projectile (122_ST) and the hollow base projectile (122_HB); this could be explained by the base drag reduction due to the base flow (base bleed) which increases the base pressure $[4,23]$.

In Tab. 3 the results of range and drift given by the 6DOF model and experimental results are shown.

Table 3 The experimental and expected results (estimated by the 6-DOF model) and the difference between them $\left(\theta_{0}=14,22^{\circ}\right)$

\begin{tabular}{|c|c|c|c|c|c|c|}
\hline \multicolumn{7}{|c|}{$\theta_{0}=14,22^{\circ}$} \\
\hline \multirow{2}{*}{$\begin{array}{l}\stackrel{0}{ت} \\
\frac{0}{0} \\
\frac{0}{2}\end{array}$} & \multicolumn{3}{|c|}{$X_{\max }(\mathrm{m})$} & \multicolumn{3}{|c|}{$Z_{\max }(\mathrm{m})$} \\
\hline & 6-DOF & EXP & $|\varepsilon \%|$ & 6-DOF & EXP & $|\varepsilon \%|$ \\
\hline $122 \mathrm{ST}$ & 10603 & 10534 & $\sim 0,65$ & 78 & $\sim 81$ & $\sim 3,85$ \\
\hline $122 \mathrm{HB}$ & 11303 & 11158 & $\sim 1,29$ & 80 & $\sim 84$ & $\sim 5,00$ \\
\hline $122 \mathrm{BB}$ & 14572 & 14300 & $\sim 1,87$ & 118 & $\sim 120$ & $\sim 1,70$ \\
\hline
\end{tabular}

From Tab. 3 it can be seen that the error between the mathematical model (6-DOF) and the experimental results is acceptable.

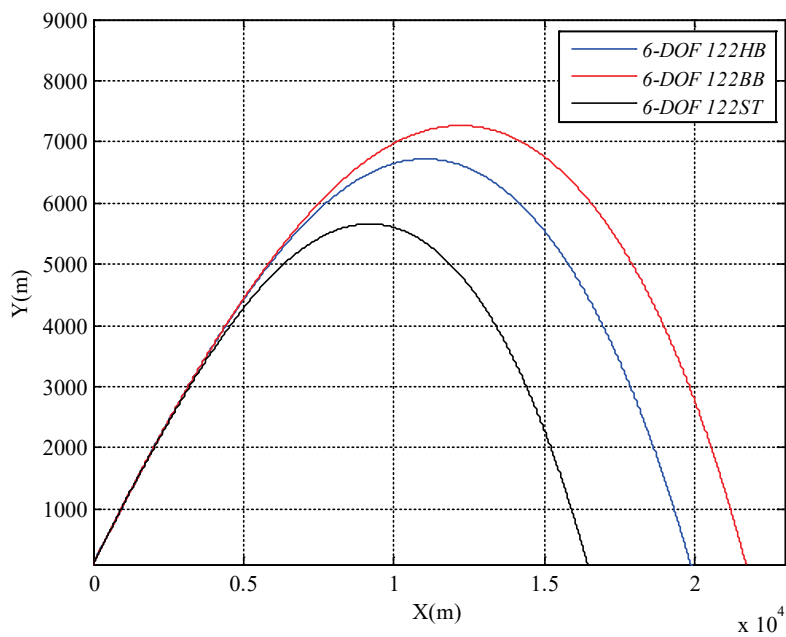

Figure 14 The estimated trajectory $(Y=f(X))$ by the 6-DOF model for the three projectile types $\left(\theta_{0}=44,70^{\circ}\right)$

For the shooting with a firing angle equal to $\theta_{0}=$ $44,70^{\circ}$, tests are done without 3-D radar capture. In the following figures (Fig. 14 and Fig. 15), the expected trajectories and the velocity evolution as a function of distance estimated by the 6-DOF model for all projectile types are summarized.

In Tab. 4 the results of range and drift given by the 6DOF model and experimental results are shown for elevation angle equal to $44,70^{\circ}$.

From Fig. 14 and Tab. 4, it can be seen that the projectile with base bleed (122_BB) presents good choice in terms of increasing the range of artillery projectiles $(\approx 33 \%)$ compared to the standard projectile (122_ST) [21]. Similarly, in the case of the hollow base projectile
(122_HB) the increasing of the projectiles range reaches up to $\approx \overline{2} 1 \%$ which confirms the effect of the change of the base shape on the projectiles range, and effectiveness of the hollow base projectile (122_HB).

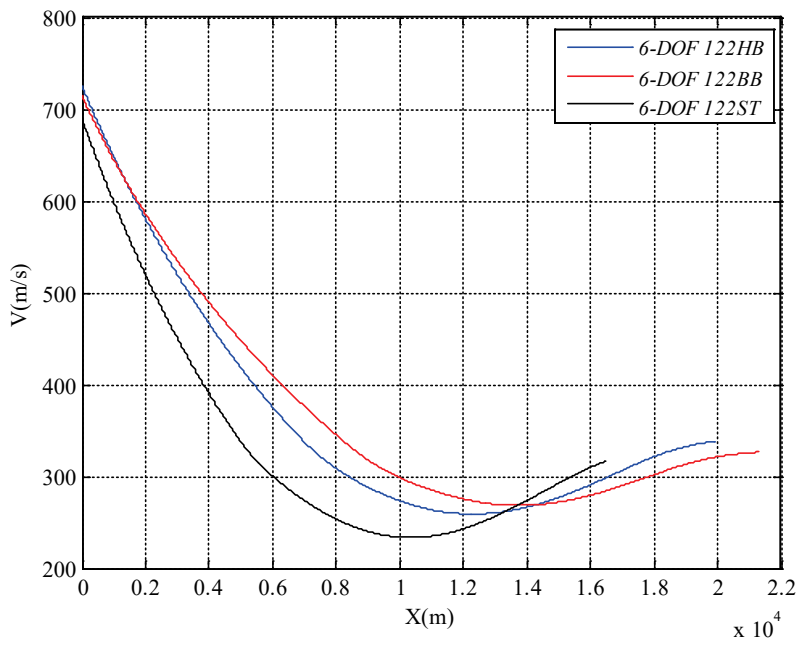

Figure 15 The estimated velocity profile $(V=f(X))$ by the 6-DOF model for the three projectile types $\left(\theta_{0}=44,70^{\circ}\right)$.

Table 4 The experimental and expected results (estimated by the 6-DOF model) and the difference between them $\left(\theta_{0}=44,70^{\circ}\right)$

\begin{tabular}{|c|c|c|c|c|c|c|}
\hline \multicolumn{7}{|c|}{$\theta_{0}=44,70^{\circ}$} \\
\hline \multirow{2}{*}{$\begin{array}{l}\frac{0}{D} \\
\frac{d}{0} \\
\stackrel{0}{0}\end{array}$} & \multicolumn{3}{|c|}{$X_{\max }(\mathrm{m})$} & \multicolumn{3}{|c|}{$Z_{\max }(\mathrm{m})$} \\
\hline & 6-DOF & EXP & $|\varepsilon \%|$ & 6-DOF & EXP & $|\varepsilon \%|$ \\
\hline 122_ST & 16450 & 16200 & $\sim 1,52$ & 485,13 & $\sim 500$ & $\sim 3,25$ \\
\hline $122 \mathrm{HB}$ & 19876 & 19700 & $\sim 0,88$ & 584,09 & $\sim 603$ & $\sim 3,24$ \\
\hline $122 \_\mathrm{BB}$ & 21878 & 21300 & $\sim 2,64$ & 625,48 & $\sim 648$ & $\sim 3,60$ \\
\hline
\end{tabular}

The velocity profiles for all projectile types (Fig. 15) decrease during flight until the peak point of the trajectory. At this highest point the transverse component of velocity vanishes $\left(V_{y}=0\right)$; after this point the projectile accelerates again under the influence of the gravity; but in some cases as for free falls, the projectile's velocity reaches a speed limit (especially during a long projectile flight); this phenomenon can be justified by the equality of the gravitational force and the drag force which gave a constant projectile speed [10].

Before every projectile arrives to its peak point, the hollow base projectile (122_HB) has a velocity reduction higher than that in the case of the projectile with base bleed (122_BB). In the case of the standard projectile (122_ST), this reduction is the highest; this difference is mainly the consequence of the difference between the base drag values for every projectile.

\section{CONCLUSION}

In order to estimate the drag force coefficient $\left(C_{D}\right)$, an axisymmetric 2D Reynolds Averaged Navier-Stokes (RANS) computational fluid dynamics (CFD) software was performed at different values of the Mach numbers for three types of projectile calibre $122 \mathrm{~mm}$ : the first one is a standard projectile (122_ST), the second one is a projectile with base bleed called (122_BB) and the third one is with hollow base shape (122_HB). The GAMBIT software was used to model and grid the (2-D) body geometry, and 
afterwards it was exported to the software ANSYSFLUENT $^{\mathrm{TM}}$ to simulate the airflow around the projectile.

The combustion products, which were obtained with the help of the thermochemical calculation, are introduced in the simulation.

The simulations were performed for the zero angle of attack and Mach number range $0,4 \leq M \leq 2,2$. For given mass flow rates we determine change of base pressure and decreasing of base and total drag. Finally, the analytic correlation between the base drag change $\left(\Delta C_{D}\right)$ as a function of impulse and flight Mach number $M$ (Eq. (13)) is created.

The Supersonic/Initial Gauge Pressure is obtained from the static experimental combustion tests and used in the CFD calculations.

The influence of the Afterbody flow effects on the drag coefficient in the case of the hollow base projectile (122 HB) using CFD calculations shows that the drag reduction reaches up to $8 \%$ compared to the standard projectile. As well, the drag reduction coefficient in the case of the projectile with base bleed (122_BB) reaches up to $20 \%$ compared to the standard projectile.

An experimental validation is made by following the projectile trajectory using the 3-D radar system model WEIBEL MFTR-2100. There was the shift between the CFD and the experimental drag coefficient results due to the noise in the signals and errors in the code calculations.

In order to confirm the axial drag coefficient reduction effect on the range of the projectiles, the CFD results are introduced as inputs in the 6-DOF trajectory estimator to obtain a theoretical trajectory for every projectile with a modification in the case of projectiles with a base bleed unit.

The comparison of the experimental and theoretical or estimated trajectories, drifts and velocity profiles shows that they are almost identical with the small difference that does not exceed $5 \%$ for the same inputs. Besides, the projectile with base bleed achieved increasing of artillery projectiles range for $33 \%$ compared to the standard projectile. Similarly, in the case of the hollow base projectile the increase of the projectile's range reaches approximately $21 \%$. This confirms the effect of the change of the base shape of projectiles on their range, and effectiveness of the hollow base projectile to increase the range of artillery projectiles due to their base drag reduction. The modified 6-DOF gave very good results compared with experimental ones. That confirms the reliability of our flight model and the possibility that it can be used for making the new firing table data.

This investigation will be continued in the future through:

- Studying the effect of the base shape of projectiles with

3-D geometry at different angles of attack on the drag force coefficient, and the effect of the latter on the range of the projectile.

- Determination of the influence of the base shape effects on the lateral aerodynamic coefficients, and especially dynamic derivatives and stability parameters using LES and DES models.

- Determination of the effect of the base bleed unit characteristics on the range of artillery projectiles with base bleed, and finding the optimal grain geometry.
- Determination of the effect of the depth of hollow base projectiles on their drag force coefficient, and finding the optimal depth, which will give the highest drag reduction.

- Validations of all these future works by radar capture of projectiles and using the wind tunnel for determination of the different lateral aerodynamic coefficients, and especially dynamic derivatives and stability parameters.

\section{REFERENCES}

[1] Lee, Y. -K. \& Kim, H. -D. (2006). Optimization of mass bleed control for base drag reduction of supersonic flight bodies. Journal of Thermal Science, 15(3), 206-212. https://doi.org/10.1007/s11630-006-0206-4

[2] Andersson, K., Gunners, N. E., \& Hellgren, R. (1976). Swedish Base Bleed - Increasing the range of artillery projectiles through base flow. Propellants, Explosives, Pyrotechnics, 1(4), 69-73. https://doi.org/10.1002/prep.19760010402

[3] Ansys Inc., ANSYS FLUENT 17.0 and GAMBIT 2.1 licensed to MA, 2017.

[4] Sahu, J., Nietubicz, C. J., \& Steger, J. L. (1983). NavierStokes Computations of Projectile Base Flow at Transonic Speeds with and without Base Injection. AIAA Journal, 23(9), 1348-1355. https://doi.org/10.21236/ada135783

[5] Belaidouni, H. Đ., Samardžić, M., Jerković, D., Živković, S., Rajić, Z., Ćurčić, D., \& Kari, A. (2018). Comparison Of Static Aerodynamic Data Obtained in Dynamic Wind Tunnel Tests and Numerical Simulation Research. Tehnički vjesnik, 25(2), 445-452. https://doi.org/10.17559/TV-20161221140914

[6] Castro, I. P. \& Apsley, D. D. (1997). Flow and dispersion over topography: A comparison between numerical and laboratory data for two-dimensional flows. Atmospheric Environment, 31(6), 839-850. https://doi.org/10.1016/s1352-2310(96)00248-8

[7] Nicolás-Pérez, F., Velasco, F. J. S., García-Cascales, J. R., Otón-Martínez, R. A., López-Belchí, A., Moratilla, D., Rey, F., \& Laso, A. (2017). On the accuracy of RANS, DES and LES turbulence models for predicting drag reduction with Base Bleed technology. Aerospace Science and Technology, 67, 126-140. https://doi.org/10.1016/j.ast.2017.03.031

[8] Orlenko, P, L. (2002). Physics of Explosion (Book in Russian). Moscow: FizMatLit.

[9] Roe, P. (1986). Characteristic-Based Schemes for the Euler Equations. Annual Review of Fluid Mechanics, 18(1), 337365. https://doi.org/10.1146/annurev.fluid.18.1.337

[10] Regodić, D. (2006). External Ballistic. (In Serbian), Belgrade, Serbia. Military Academy.

[11] Walters, D. K. \& Cokljat, D. (2008). A Three-Equation Eddy-Viscosity Model for Reynolds-Averaged NavierStokes Simulations of Transitional Flow. Journal of Fluids Engineering, 130(12), 121401. https://doi.org/10.1115/1.2979230

[12] McCoy, R. L. (2012). Modern exterior ballistics: the launch and flight dynamics of symmetric projectiles. Atglen, PA: Schiffer Pub.

[13] Fresconi, F., Cooper, G., Celmins, I., Despirito, J., \& Costello, M. (2010). Flight Mechanics of a Novel Guided Spin-Stabilized Projectile Concept. AIAA Atmospheric Flight Mechanics Conference. https://doi.org/10.2514/6.2010-7638

[14] Thuresson. M. (2015). Development and Evaluation of a Six Degrees of Freedom Model of a $155 \mathrm{~mm}$ Artillery Projectile. Stockholm. Degree project, in mechatronics, second level.

[15] Gkritzapis, D. N., Panagiotopoulos, E. E., Margaris, D. P., Papanikas, D. G., Simos, T. E., \& Maroulis, G. (2007). A Six 
Degree of Freedom Trajectory Analysis of Spin-Stabilized Projectiles. AIP Conference Proceedings. https://doi.org/10.1063/1.2835958.

[16] Jankovic, S. (1978). Aerodynamics of projectiles (In Serbian). Belgrade. Faculty of Mechanical Engineering.

[17] Petrov, K, P. (1977). Aerodynamics of rockets (In Russian). Moscow. Masi-nostroenie.

[18] ISO International Standard 2533-1975. (1978). Standard Atmosphere first edition, corrigendum 1, ISO, Geneva, Switzerland.

[19] Bowman, J. E. \& Clayden, W. (1969). A Reduction of Base Drag by Gas Ejection. R.A.R.D.E. report 1969, 4/64.

[20] Jaramaz, S. \& Injac, M. (1988). Effect of Grain Characteristics on Range of Artillery Projectiles with Base Bleed. International Journal of Energetic Materials and Chemical Propulsion, 1(1-6), 143-157. https://doi.org/10.1615/intjenergeticmaterialschemprop.v1.i16.110 .

[21] Jaramaz, S. \& Injac, M. (1989). Method of Calculation Range of Base Bleed Projectile. (In Serbian), Military Technical Institute, Belgrade.

[22] Weibel Scientific Solvang. MFTR 2100 Medium Range TSPI \& Debris Radar. MFTR-2100/40 \& MFTR2100/43Specification. Report ID CS-1017-006. Weibel Doppler Radars. Allerød Denmark, 2010. www.weibel.dk

[23] Regodić, D., Jevremović, A., \& Jerković, D. (2013). The prediction of axial aerodynamic coefficient reduction using base bleed. Aerospace Science and Technology, 31(1), 2429. https://doi.org/10.1016/j.ast.2013.09.001

[24] Kubberud, N. \& Ivar, J. Ø. (2011). Extended range of $155 \mathrm{~mm}$ projectile using an improved BaseBleed unit Simulations and Evaluation. 26 $6^{\text {th }}$ International Symposium on Ballistics, 12-16 September 2011.

[25] Baranowski, L. (2013). Equations of Motion of a SpinStabilized Projectile for Flight Stability Testing. Journal of Theoretical and Applied Mechanics, 51(1). 235-246.

\section{NOTATIONS}

\section{Symbol Description}

a Burning low constant

$A_{b} \quad$ The base surface of the projectile $\left(\mathrm{m}^{2}\right)$

$A_{i} \quad$ Surface of base bleed orifice $\left(\mathrm{m}^{2}\right)$

$A_{\text {ref }} \quad$ Reference projectile surface

$b \quad$ Coefficient in burning low

$C_{D} \quad$ Drag force coefficient

$C_{L_{\alpha}} \quad$ Lift force coefficient

$C_{N P \alpha} \quad$ Magnus force coefficient

$C_{N \alpha} \quad$ Normal force coefficient derivate

$C_{l p} \quad$ Spin damping moment coefficient

$C_{M \alpha} \quad$ Overturning moment coefficient

$C_{M P \alpha} \quad$ Magnus moment coefficient

$C_{M q} \quad$ Pitch damping moment coefficient

$C_{D B B} \quad$ Drag force coefficient for the projectiles with base

bleed

$d \quad$ Projectile caliber $(\mathrm{m})$

$\boldsymbol{g} \quad$ Acceleration due to gravity $\left(\mathrm{m} / \mathrm{s}^{2}\right)$

$\boldsymbol{h} \quad$ Angular momentum $\left(\mathrm{kg} \cdot \mathrm{m}^{2} / \mathrm{s}\right)$

I Impulse defined by Eq. (11)

$I_{z} \quad$ Transverse moment of Inertia $\left(\mathrm{kg} \cdot \mathrm{m}^{2}\right)$

$I_{x} \quad$ Axial moment of Inertia $\left(\mathrm{kg} \cdot \mathrm{m}^{2}\right)$

$k \quad$ Specific heat ratio of burning products

$\begin{array}{ll}m & \text { Mass }(\mathrm{kg}) \\ M & \text { Molecular weight of burning products }(\mathrm{kg} / \mathrm{mol}) \\ M_{\infty} & \text { Mach flight number } \\ \dot{m}_{b} & \text { Mass flux of the air at the base of projectile } \\ \dot{m}_{g} & \text { Mass flux of the burning products from burning } \\ n & \text { surface } \\ p & \text { Exponent in burning low } \\ P_{g} & \text { Axial rotation speed (spine) (rad } / \mathrm{s}) \\ r & \text { Pressure in base bleed } \\ R_{g} & \text { Gas constant of burning products } \\ S & \left.\text { Projected front area of the projectile ( } \mathrm{m}^{2}\right) \\ t_{g} & \text { Working time of base bleed } \\ T_{g} & \text { Burning products temperature } \\ \boldsymbol{V} & \text { Velocity (m/s) } \\ V_{\infty} & \text { Projectile velocity (m/s) } \\ \boldsymbol{W} & \text { Wind speed (m/s) } \\ \boldsymbol{x} & \text { Unit vector along the projectile's axis of symmetry } \\ v & \text { Total velocity (m/s) } \\ \rho & \text { Density }\left(\mathrm{kg} / \mathrm{m}^{3}\right) \\ \boldsymbol{\Lambda} & \text { Acceleration due to Coriolis Effect } \\ \Delta C_{D} & \text { Drag reduction coefficient }\end{array}$

\section{Contact information:}

Mohammed Amin DALI, PhD Student (CA)

University of Defence, Military Academy,

Pavla Jurisica Sturma 33, 11000, Belgrade, Serbia

E-mail: DaliMA380@gmail.com

Slobodan JARAMAZ, Professor

University of Belgrade, Faculty of Mechanical Engineering,

Kraljice Marije 16, 11000 Belgrade, Serbia

E-mail: sjaramaz@mas.bg.ac.rs

Damir JERKOVIC, Assistant Professor

University of Defence, Military Academy,

Pavla Jurisica Sturma 33, 11000, Belgrade, Serbia

E-mail: damir.jerkovic@va.mod.gov.rs

Danilo DJURDJEVAC, researcher

Military Technical Institute,

Ratka Resanovića 1, 11000, Belgrade, Serbia

E-mail: danilo.djurdjevac@vti.vs.rs 